\title{
Machiavellian Sebagai Variabel Moderasi Pada Pengaruh Audit Fee Terhadap Disfungsional Auditor
}

\author{
Fitria Magdalena Suprapto \\ Universitas Islam Kadiri, fitria.magdalena@uniska-kediri.ac.id
}

\begin{abstract}
ABSTRAK
Penelitian ini bertujuan untuk menguji pengaruh machiavellian sebagai variabel moderasi pada audit fee terhadap disfungsional auditor. Metode penelitian yang digunakan adalah kuantitatif dengan sumber data primer melalui pengumpulan data kuesioner yang disebarkan dengan mempertimbangkan beberapa kriteria tertentu atau purposive sampling. Dari 100 responden yang disebar, sebanyak 66 yang memenuhi kriteria sebagai sampel dan dapat diolah menggunakan regresi linear dan moderated regression analysis. Hasil penelitian menunjukkan bahwa variabel audit fee berpengaruh negatif terhadap disfungsional auditor karena fee atas pekerjaan audit yang dinilai terlalu rendah menyebabkan auditor menyelesaikan pekerjaan yang terlalu cepat. Tekanan yang dialami auditor dari manajemen tingkat atas ke bawah ini akan mendorong perilaku tereduksinya kualitas audit atau perilaku disfungsional auditor, sementara machiavellian tidak mampu memoderasi audit fee terhadap disfungsional auditor karena tidak adanya komitmen dalam menjaga integritas akan menaikkan perilaku disfungsional auditor. Penelitian ini berkontribusi pada perusahaan dan regulator karena atas audit fee yang dikeluarkan akan menentukan tindakan disfungsional yang dilakukan oleh auditor, sehingga regulator dapat mempertimbangkan regulasi yang adil atas penentuan batasan audit fee.
\end{abstract}

Kata Kunci: audit fee, disfungsional auditor, dan machiavellian

\begin{abstract}
This study aims to examine the effect of Machiavellian as a moderating variable on audit fees on dysfunctional auditors. The research method used is quantitative with primary data sources through the collection of questionnaire data distributed by considering certain criteria or purposive sampling. Of the 100 respondents distributed, as many as 66 who meet the criteria as a sample and can be processed using linear regression and moderate regression analysis. The results show that the audit fee variable has a negative effect on auditor dysfunction because the fee for audit work that is considered too low causes the auditor to complete the work too quickly. The pressure experienced by auditors from top to bottom management will encourage reduced audit quality behavior or auditor dysfunctional behavior, while Machiavellian is unable to moderate audit fees for dysfunctional auditors because the absence of commitment to maintaining integrity will increase auditor dysfunctional behavior. This research contributes to companies and regulators because the audit fees incurred will determine the dysfunctional actions taken by the auditors, so that regulators can consider fair regulation of audit fees.
\end{abstract}

Keywords: audit fee, dysfunctional auditor, and machiavellian

Naskah diterima : 20-08-2021, Naskah dipublikasikan : 30-11-2021 


\section{JURNAL AKUNTANSI, Vol. 10, No. 2, November (2021)}

\section{PENDAHULUAN}

Laporan keuangan merupakan media bagi manajemen dalam mempertanggungjawabkan pengelolaan kekayaan perusahaan yang telah dipercayakan oleh shareholder. Manajemen wajib menyajikan laporan keuangan secara periodik agar shareholder mampu memverifikasi kondisi perusahaan yang sesungguhnya. Untuk itu, kandungan laporan keuangan harus memenuhi empat karakteristik kualitatif, yaitu: dapat dipahami, relevan, andal, dan dapat diperbandingkan. Cara yang dapat digunakan untuk mengujinya adalah dengan menggunakan jasa auditor.

Agar tidak menyesatkan, shareholder dan pemangku kepentingan lainnya harus memastikan mutu audit atas laporan keuangan tidak direduksi atau terhindar dari perilaku disfungsional auditor. Asrini dkk (2014) menyatakan bahwa sikap profesional dan independen berguna saat memberikan jasa audit untuk meningkatkan kualitas informasi. Skandal fenomenal yang mengabaikan kedua hal tersebut adalah kasus kelalaian KAP Tanubrata, Sutanto, Fahmi, Bambang, dan Rekan dalam mengaudit laporan keuangan tahun 2018 PT Garuda Indonesia. Hasil audit dari Akuntan Publik Kasner Sirumapea mendapat penolakan dari dua komisaris karena dinilai tidak tepat dalam menilai substansi transaksi pengakuan pendapatan serta tidak mampu menghadirkan fakta-fakta peristiwa setelah tanggal neraca.

Situasi pandemi Covid-19 yang dialami oleh seluruh dunia menyebabkan Indonesia diambang pintu resesi. Masyarakat diharap bersiap menghadapi resesi ekonomi yang diproyeksikan oleh Menteri Keuangan Sri Mulyani pada kuartal III-2020 (www.kompas.com). Dampak negatif yang akan dirasakan oleh masyarakat adalah inflasi dan meningkatnya angka pengangguran. Tak terkecuali pada profesi akuntansi. Jika mengalami hal demikian, manusia pasti akan melakukan berbagai cara demi keberlangsungan hidup dan usaha.

Muhshyi (2013) menyebutkan adanya dilemma cost-quality menyebabkan auditor menurunkan kualitas audit atau perilaku disfungsional auditor. Hal ini dikarenakan adanya ketidakseimbangan antara audit fee yang diterima dengan kualitas yang diatur oleh standar profesional. Auditor akan cenderung menerima perikatan dengan fee rendah meskipun hal itu berisiko menyebabkan time budget tidak diukur dengan akurat dan menjadi singkat karena adanya ancaman pergantian auditor akibat perusahaan kesulitan dalam membayar audit fee yang terlalu tinggi (Suprapto dan Nugroho, 2020). Integritas dan kejujuran yang perlu dimiliki oleh setiap jiwa auditor mungkin akan diabaikan karena menganggap hal tersebut tidak lebih penting daripada menjaga perikatan klien agar terus berlanjut. Sifat Machiavellian ini mungkin akan dimiliki oleh individu yang tidak memiliki perencanaan keuangan yang matang sebab pekerjaan audit diselesaikan dengan mengabaikan faktor integritas dan sangat menekan budget. Perencanaan anggaran sebelum implementasi tugas audit mutlak diperlukan agar terhindar dari perilaku disfungsional auditor (Riny, 2015). Hal ini berbeda dengan hasil penelitian yang dilakukan oleh Dhimandhanu (2016) yang menyebutkan bahwa fee audit tidak dapat menjadi tolok ukur keberhasilan audit. Pemberian opini wajar tanpa pengecualian tidak disebabkan pemberian fee audit yang tinggi sehingga dapat mempengaruhi keputusan auditor. Adanya ketidakkonsistenan hasil penelitian ini mendorong peneliti untuk menguji pengaruh audit fee terhadap perilaku disfungsional auditor dengan menjadikan sifat machiavellian sebagai variabel moderasi.

\section{KAJIAN LITERATUR}

\section{Teori Pengharapan}

Griffin (2002) menyatakan bahwa pengharapan tergantung pada dua hal, yaitu seberapa usaha kita saat menginginkan sesuatu dan seberapa kemungkinan hal itu dapat tercapai. Asumsi dasar dari teori ini adalah: pertama, tindakan dipengaruhi oleh kombinasi antara faktor dalam diri individu dan lingkungan. Kedua, individu memutuskan sendiri perilaku yang dipilih. Ketiga, adanya perbedaan tipe kebutuhan, keinginan, dan tujuan yang dimiliki individu. Keempat, 


\section{JURNAL AKUNTANSI, Vol. 10, No. 2, November (2021)}

banyaknya alternatif perilaku membuat individu memilih perilaku berbasis persepsi pengharapan atas hasil.

Teori pengharapan memotivasi auditor untuk dapat mengatur waktu dalam menyelesaikan tugas audit. Ketika dihadapkan pada kondisi sulit, maka auditor cenderung berperilaku yang bertentangan dengan prosedur audit. Latar belakang yang memotivasi auditor untuk melakukan tindakan tersebut adalah sebagai upaya untuk mempertahankan diri.

\section{Disfungsional Auditor}

Perilaku menurunkan atau mereduksi kualitas audit merupakan tindakan menyimpang yang berpengaruh terhadap mutu laporan auditor. Shareholder dan pemangku kepentingan telah mempercayakan jasa auditor dalam menilai laporan keuangan untuk mengambil keputusan namun kepercayaan tersebut diselewengkan. Hasil audit yang diberikan tidak mampu mencerminkan kewajaran dan menemukan salah saji atas laporan keuangan (Suprapto dan Nugroho, 2020).

\section{Audit Fee}

Penawaran audit fee yang terjadi di KAP bukan merupakan suatu ketetapan yang disesuaikan dengan standar. Hal ini melewati proses negosiasi pada tahap awal perikatan yang diharapkan dapat menguntungkan kedua belah pihak. Penawaran besaran imbalan yang didapat ini akan berdampak terhadap auditor sebagai dasar pembebanan waktu dan biaya dalam menjalankan keahliannya. Ketika klien tidak menyetujui dengan besaran fee yang harus diberikan, maka akan memotivasi terjadinya pergantian KAP (Damayanti dan Sudarma, 2008) yang nantinya akan berpengaruh pada hilangnya sumber pendapatan KAP. Namun, jika KAP terpaksa untuk menerima perikatan maka akan berdampak terhadap dasar pembebanan waktu dan biaya yang dikeluarkan auditor dalam menjalan tugas. Hal ini sesuai dengan hasil penelitian Kiryanto dan Tyas (2015) dan Santoso dan Achmad (2019).

$\mathrm{H}_{1}$ : Audit fee berpengaruh terhadap disfungsional auditor

\section{Sifat Machiavellian}

Sifat machiavellian cenderung digambarkan dengan individu yang oportunis (Martini dan Pertama, 2019). Individu tersebut akan lebih manipulatif dan agresif yang mendekatkan pada perilaku disfungsional. Perilaku yang dilema secara etis akan melakukan segala upaya demi mencapai tujuan yang ingin dikehendakinya. Auditor dengan sifat machiavellian tidak memiliki independensi dan profesionalisme serta cenderung berperilaku menghalalkan segala cara demi mencapai tujuan (Saputri dan Wirama, 2015). Hal ini didukung oleh penelitian Avi (2018), Afsari (2018), Martini dan Pertama (2019), dan Putri (2020).

$\mathrm{H}_{2}$ : Machiavellian memoderasi audit fee terhadap disfungsional auditor

Berdasarkan penjelasan di atas, maka kerangka pikir yang dapat dibentuk adalah:

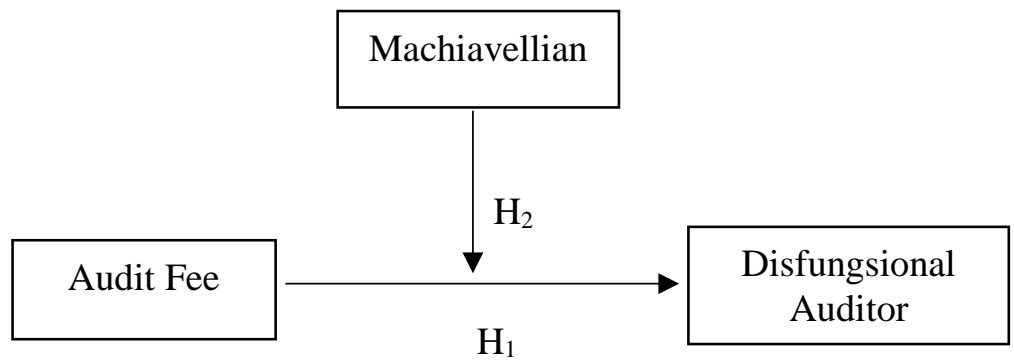

Gambar 1. Kerangka Berpikir 


\section{METODE PENELITIAN}

Berdasarkan latar belakang penelitian, jenis penelitian ini adalah kuantitatif dengan sumber data primer yang berasal dari pengumpulan data opini individu melalui jawaban kuesioner terhadap responden (Sugiyono, 2011:225). Angket yang disebarkan menggunakan skala likert 1 sampai dengan 5 yang menyatakan sikap seseorang atas keadaan tertentu. Teknik analisis data menggunakan regresi linear dengan bantuan SPSS untuk mengetahui pengaruh audit fee terhadap disfungsional auditor yang dimoderasi oleh sifat machiavellian.

Populasi penelitian ini adalah auditor pada KAP yang berlokasi di Surabaya. Metode purposive sampling atau dengan mempertimbangkan beberapa kriteria tertentu dipilih sebagai teknik pengambilan sampel, yaitu:

1. Auditor memiliki pengalaman bekerja minimal satu tahun pada KAP di Surabaya.

2. Auditor telah ditugaskan dalam kerja lapangan dan telah menyelesaikannya.

Tabel 1.Data Sampel Penelitian

\begin{tabular}{|l|c|}
\hline \multicolumn{1}{|c|}{ Keterangan } & Jumlah \\
\hline Kuesioner yang disebar & 100 \\
\hline Kuesioner yang tidak kembali & $(25)$ \\
\hline Kuesioner yang tidak dapat diolah & $(9)$ \\
\hline Jumlah sampel penelitian & $\mathbf{6 6}$ \\
\hline Tingkat Pengembalian (\%) & $\mathbf{6 6 \%}$ \\
\hline
\end{tabular}

Sumber : Data penelitian, 2021

\section{PEMBAHASAN}

\section{Data Demografi Responden}

Penelitian ini menggunakan profesi auditor yang telah bekerja di Kantor Akuntan Publik di Surabaya sebagai responden. Terdapat 66 kuesioner yang dapat diolah dari 100 kuesioner yang telah disebar. Tingkat pengembalian kueisoner sebesar $66 \%$.

Menurut karakteristik demografi responden, responden dengan jenis kelamin perempuan lebih mendominasi sebesar 36 orang (55\%) sedangkan sisanya berjenis kelamin laki-laki sebanyak 30 orang $(45 \%)$. Usia responden mayoritas kurang dari 30 tahun $(94 \%)$ dengan jabatan junior sebanyak $71 \%$, senior $18 \%$, dan supervisor $11 \%$. Sebanyak 57 orang responden dengan pengalaman kerja kurang dari 5 tahun (85\%). Responden mayoritas memiliki gelar S1 sebesar $79 \%$, sisanya telah menempuh Diploma dan S2. 
JURNAL AKUNTANSI, Vol. 10, No. 2, November (2021)

\section{Hasil Uji Validitas dan Reliabilitas}

Tabel 2. Hasil Uji Validitas

\begin{tabular}{lccc}
\hline \multicolumn{1}{c}{ Variabel } & $\begin{array}{c}\text { Kode } \\
\text { Indikator }\end{array}$ & $\begin{array}{c}\text { Pearson } \\
\text { Correlation }\end{array}$ & Keterangan \\
\hline Audit Fee & AF1 & 0,698 & Valid \\
& AF2 & 0,626 & Valid \\
& AF3 & 0,650 & Valid \\
& AF4 & 0,728 & Valid \\
& AF5 & 0,424 & Valid \\
Machiavellian & M1 & 0,626 & Valid \\
& M2 & 0,579 & Valid \\
& M3 & 0,539 & Valid \\
& M4 & 0,484 & Valid \\
& M5 & 0,447 & Valid \\
Disfungsional Auditor & DA1 & 0,334 & Valid \\
& DA2 & 0,852 & Valid \\
& DA3 & 0,821 & Valid \\
& DA4 & 0,761 & Valid \\
\hline
\end{tabular}

Sumber: Data Penelitian, 2021

Dapat diketahui dari tabel di atas yang menunjukkan nilai pearson correlation seluruh indikator atas variabel yang diteliti di atas 0,3 . Artinya bahwa semua indikator penelitian dari variabel tersebut valid atau memenuhi syarat uji validitas.

Tabel 3. Hasil Uji Reliabilitas

\begin{tabular}{lcl}
\hline \multicolumn{1}{c}{ Variabel } & $\begin{array}{c}\text { Cronbach's } \\
\text { Alpha }\end{array}$ & Keterangan \\
\hline Audit Fee & 0,610 & Reliabel \\
Machiavellian & 0,630 & Reliabel \\
Disfungsional Auditor & 0,656 & Reliabel \\
\hline
\end{tabular}

Sumber: Data Penelitian, 2021

Menurut tabel di atas yang menunjukkan nilai cronbach's alpha dari variabel penelitian di atas 0,6 sehingga dinyatakan reliabel. 


\section{Hasil Uji Asumsi Klasik}

\section{Uji Normalitas}

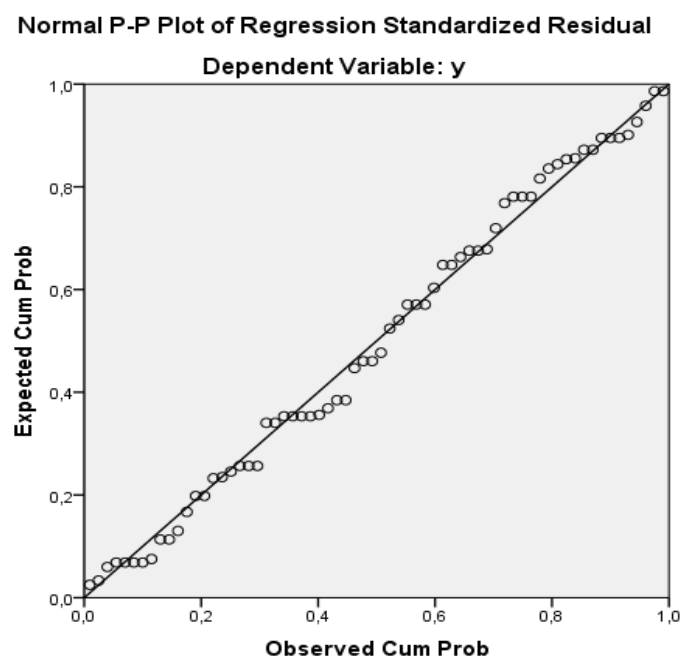

Gambar 2. Hasil Uji Normalitas Model 1

Sumber: Data Penelitian, 2021

Untuk menguji apakah variabel penelitian berdistribusi normal atau tidak, penelitian ini menggunakan sebaran data (titik) pada sumbu diagonal dari grafik. Pada penelitian ini model 1 regresi normal karena sebaran data (titik) berada disekitar garis diagonalnya. Hasil dari olah SPSS juga menunjukkan bahwa variabel penelitian terdistribusi normal karena tingkat signifikansinya $\geq 0,050,05$. Hal ini terlihat dari nilai kolmogorovsmirnov $\mathrm{Z}$ sebesar 0,575 dengan tingkat signifikan 0,895 .

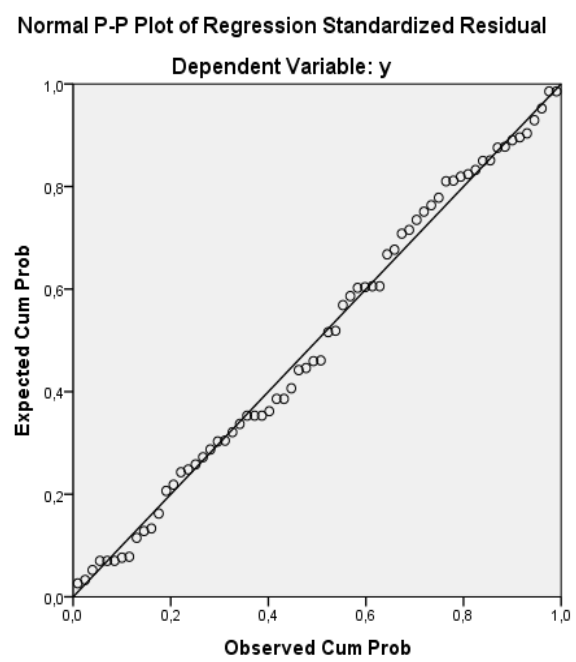

Gambar 3. Hasil Uji Normalitas Model 2

Sumber: Data Penelitian, 2021 


\section{JURNAL AKUNTANSI, Vol. 10, No. 2, November (2021)}

Menurut gambar di atas, model 2 regresi dikatakan terdistribusi normal karena sebaran titik mengikuti arah garis diagonalnya. Hasil dari olah SPSS juga memperlihatkan bahwa variabel penelitian ini terdistribusi normal yang dibuktikan dari nilai kolmogorovsmirnov Z sebesar 0,474 dengan tingkat signifikan 0,978 .

\section{Uji Multikolinieritas}

Tabel 4. Hasil Uji Multikolinieritas

\begin{tabular}{llcc}
\hline \multirow{2}{*}{ Model } & \multicolumn{2}{c}{ Collinearity Statistics } \\
\cline { 3 - 4 } & & Tolerance & VIF \\
\hline \multirow{2}{*}{1} & Audit Fee & 0,987 & 1,013 \\
& Machiavellian & 0,987 & 1,013 \\
\hline \multicolumn{2}{l}{ Dependent Variable: Disfungsional Auditor } \\
\hline
\end{tabular}

Sumber: Data Penelitian, 2021

Menurut tabel hasil uji di atas, seluruh variabel bebas bernilai tolerance di atas 0,1 . Sedangkan VIF bernilai di bawah 10. Hal ini berarti bahwa data dalam penelitian ini terbebas dari multikolinearitas.

\section{Uji Heteroskedastisitas}

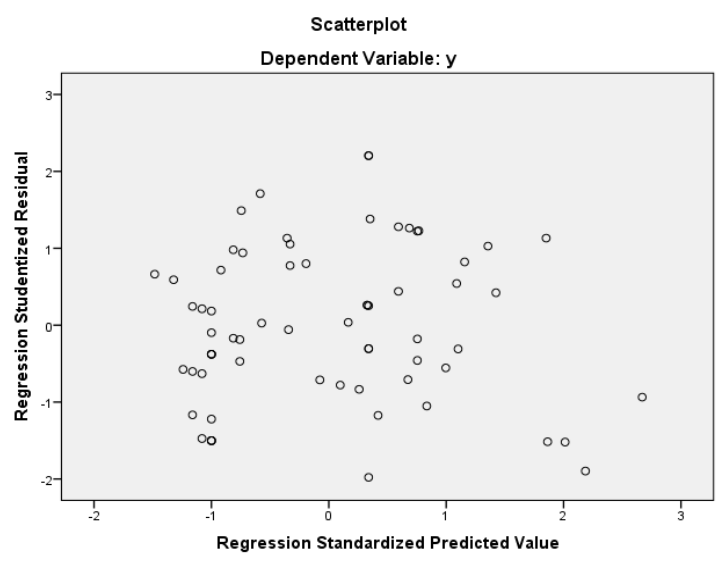

Gambar 4. Hasil Uji Heteroskedastisitas

Sumber: Data Penelitian, 2021

Untuk menguji heteroskedastisitas dalam penelitian ini ialah dengan melihat pola. Uji heteroskedastisitas bertujuan untuk melihat apakah telah terjadi perbedaan varians dari residual pengamatan satu terhadap pengamatan yang lain dalam sebuah model regresi. Dalam penelitian ini tidak mengalami heteroskedastisitas yang dilihat dari gambar di atas memperlihatkan pola yang menyebar pada sumbu Y. 


\section{Uji Moderated Regression Analysis (MRA)}

Pada penelitian ini, metode yang digunakan untuk menguji hipotesis adalah Moderated Regression Analysis (MRA):

$\mathrm{DA}=\alpha+\beta 1 \mathrm{AF}+\varepsilon$

$\mathrm{DA}=\alpha+\beta 1 \mathrm{AF}+\beta 2 \mathrm{M}+\beta 3 \mathrm{AFM}+\varepsilon$

Keterangan:

$$
\begin{array}{ll}
\mathrm{DA} & =\text { Disfungsional Auditor } \\
\alpha & =\text { Bilangan konstanta } \\
\beta & =\text { Koefisien arah persamaan penelitian } \\
\mathrm{AF} & =\text { Audit Fee } \\
\mathrm{M} & =\text { Machiavellian } \\
\varepsilon & =\text { Error }
\end{array}
$$

Tabel 5. Hasil Analisis Regresi Sederhana (Model 1)

\begin{tabular}{lcccccc}
\hline & \multicolumn{2}{c}{$\begin{array}{c}\text { Unstandardized } \\
\text { Coefficients }\end{array}$} & \multicolumn{2}{c}{$\begin{array}{c}\text { Standardized } \\
\text { Coefficients }\end{array}$} & & \\
\cline { 2 - 4 } & Model & B & Std. Error & Beta & t & Sig. \\
\hline 1 (Constant) & 19,978 & 3,323 & & 6,011 & 0,000 \\
Audit Fee & $-0,425$ & 0,150 & $-0,334$ & $-2,832$ & 0,006 \\
\hline \multicolumn{7}{l}{ a. Dependent Variable: Disfungsional Auditor } \\
\hline
\end{tabular}

Sumber: Data Penelitian, 2021

Menurut tabel di atas yang menunjukkan nilai koefisien pengaruh audit fee terhadap disfungsional auditor, didapatkan persamaan penelitian yang dibentuk adalah:

$\mathrm{DA}=\alpha+\beta 1 \mathrm{AF}+\varepsilon$

Disfungsional Auditor $=19,978-0,425(\mathrm{AF})+\varepsilon$

Tabel 6. Hasil Analisis MRA (Model 2)

\begin{tabular}{llccccc}
\hline & & \multicolumn{2}{c}{$\begin{array}{c}\text { Unstandardized } \\
\text { Coefficients }\end{array}$} & $\begin{array}{c}\text { Standardized } \\
\text { Coefficients }\end{array}$ & $\mathrm{t}$ & Sig. \\
\cline { 3 - 7 } & \multicolumn{1}{c}{ Model } & B & Std. Error & Beta & & \\
\hline \multirow{2}{*}{1} & (Constant) & 13,375 & 19,009 & & 0,704 & 0,484 \\
& Audit Fee & $-0,049$ & 0,840 & $-0,038$ & $-0,058$ & 0,954 \\
& Machiavellian & 0,384 & 1,051 & 0,312 & 0,365 & 0,716 \\
& Audit Fee.Machiavellian & $-0,022$ & 0,047 & $-0,476$ & $-0,470$ & 0,640 \\
\hline
\end{tabular}

a. Dependent Variable: Disfungsional Auditor

Sumber: Data Penelitian, 2021 


\section{JURNAL AKUNTANSI, Vol. 10, No. 2, November (2021)}

Tabel di atas memperlihatkan nilai koefisien regresi dari variabel audit fee setelah dimoderasi oleh variabel machiavellian, nilai konstanta dari variabel disfungsional auditor, serta nilai signifikansi dari masing-masing variabel. Persamaan yang diperoleh:

$\mathrm{DA}=\alpha+\beta 1 \mathrm{AF}+\beta 2 \mathrm{M}+\beta 3 \mathrm{AFM}+\varepsilon$

Difungsional Auditor $=13,375-0,049(\mathrm{AF})+0,384(\mathrm{M})-0,022(\mathrm{AFM})+\varepsilon$

\section{Hasil Uji Hipotesis}

\section{Koefisien Determinasi (R2)}

Tabel 7. Hasil Uji Koefisien Determinasi Model 1

\begin{tabular}{lllll}
\hline Model & $\mathrm{R}$ & $\begin{array}{l}\mathrm{R} \\
\text { Square }\end{array}$ & $\begin{array}{l}\text { Adjusted } \\
\mathrm{R} \text { Square }\end{array}$ & $\begin{array}{l}\text { Std. Error of } \\
\text { the Estimate }\end{array}$ \\
\hline 1 & $0,334^{\mathrm{a}}$ & 0,111 & 0,097 & 3,603 \\
\hline \multicolumn{5}{l}{ a. Predictors: (Constant), Audit Fee } \\
\hline
\end{tabular}

Sumber: Data Penelitian, 2021

Menurut tabel di atas, nilai Adjusted $R$ Square penelitian sebesar 0,097 (9,7\%). Hal ini menunjukkan bahwa variasi variabel independen audit fee yang diuji dapat menjelaskan variasi perubahan variabel dependen disfungsional auditor sebesar 9,7\%, sedangkan sisanya di luar model penelitian.

Tabel 8. Hasil Uji Koefisien Determinasi Model 2

\begin{tabular}{lllll}
\hline Model & $\mathrm{R}$ & $\begin{array}{l}\mathrm{R} \\
\text { Square }\end{array}$ & $\begin{array}{l}\text { Adjusted } \\
\mathrm{R} \text { Square }\end{array}$ & $\begin{array}{l}\text { Std. Error of } \\
\text { the Estimate }\end{array}$ \\
\hline 1 & $0,349^{\mathrm{a}}$ & 0,122 & 0,079 & 3,639 \\
\hline
\end{tabular}

a. Predictors: (Constant), AFM, M, Audit Fee

Sumber: Data Penelitian, 2021

Menurut tabel di atas, nilai Adjusted $R$ Square penelitian ini sebesar 0,079 atau 7,9\%. Hal ini berarti bahwa variasi variabel independen dalam penelitian ini setelah dimoderasi oleh variabel pemoderasi dapat menjelaskan variasi perubahan variabel dependen sebesar 7,9\%. Sisanya, dipengaruhi oleh variabel di luar model penelitian.

Uji t

Tabel 9. Hasil Uji t (Parsial) Model 1

\begin{tabular}{|c|c|c|c|c|c|c|}
\hline & \multirow[b]{2}{*}{ Model } & \multicolumn{2}{|c|}{$\begin{array}{l}\text { Unstandardized } \\
\text { Coefficients }\end{array}$} & \multirow{2}{*}{$\begin{array}{c}\text { Standardized } \\
\text { Coefficients } \\
\text { Beta } \\
\end{array}$} & \multirow[b]{2}{*}{$\mathrm{t}$} & \multirow[b]{2}{*}{ Sig. } \\
\hline & & $\mathrm{B}$ & Std. Error & & & \\
\hline \multirow[t]{2}{*}{1} & (Constant) & 19,978 & 3,323 & & 6,011 & 0,000 \\
\hline & Audit Fee & $-0,425$ & 0,150 & $-0,334$ & $-2,832$ & 0,006 \\
\hline
\end{tabular}

a. Dependent Variable: Disfungsional Auditor

Sumber: Data Penelitian, 2021 


\section{JURNAL AKUNTANSI, Vol. 10, No. 2, November (2021)}

Menurut tabel di atas, variabel independen audit fee menunjukkan nilai t -2,832 dengan signifikansi 0,006 atau $<0,05$. Arti dari nilai signifikan $<A l p h a$ adalah secara parsial variabel independen berpengaruh terhadap variabel dependen sehingga audit fee berpengaruh terhadap disfungsional auditor

Tabel 10. Hasil uji t (Parsial) Model 2

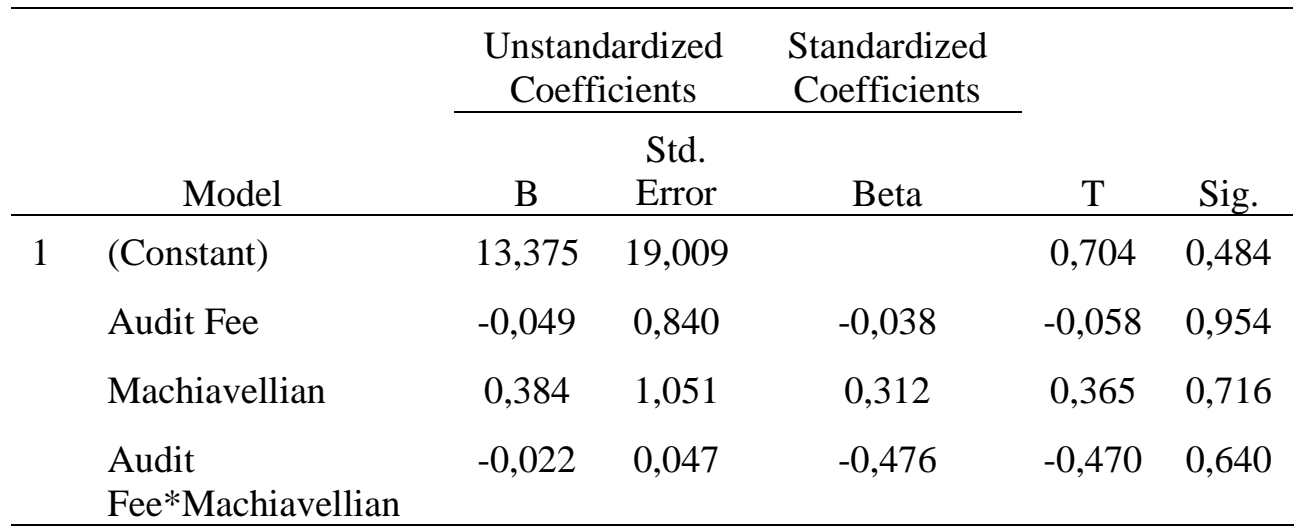

a. Dependent Variable: Disfungsional Auditor

Sumber: Data Penelitian, 2021

Menurut tabel di atas, variabel moderasi penelitian ini yaitu machiavellian memiliki nilai $\mathrm{t}-0,470$ dengan signifikansi $0,640(>0,05)$. Hal ini menunjukkan bahwa variabel moderasi dalam penelitian ini secara parsial tidak berpengaruh pada audit fee terhadap disfungsional auditor.

\section{Uji F}

Tabel 11. ANOVA

\begin{tabular}{llccccc}
\hline Model & & Sum of Squares & Df & Mean Square & F & Sig. \\
\hline 1 & Regression & 113,753 & 3 & 37,918 & 2,863 & $0,044^{\mathrm{b}}$ \\
& Residual & 821,232 & 62 & 13,246 & & \\
& Total & 934,895 & 65 & & & \\
\hline
\end{tabular}

a. Dependent Variable: Disfungsional Auditor

b. Predictors: (Constant), AFM, Audit Fee, Machiavellian

Sumber: Data Penelitian, 2021

Nilai F-tabel $=\mathrm{F}(\alpha ; \mathrm{dfn} / \mathrm{dfd}) \alpha$ yang ditunjukkan pada tabel di atas digunakan untuk menguji nilai statistik dalam penelitian ini. Nilai $\mathrm{df}$ atas $=\mathrm{dfn}=3$ dan $\mathrm{df}$ bawah $=\mathrm{dfd}=62$, sehingga didapatkan $\mathrm{F}(0,05 ; 3 / 62)$ yang menunjukkan nilai sebesar 2,75 . Fhitung $=2,863$ dengan nilai Sig.hitung $=0,044$. 


\section{JURNAL AKUNTANSI, Vol. 10, No. 2, November (2021)}

\section{Pembahasan Hasil Analisis}

Tabel 12. Hasil Analisis Hipotesis

\begin{tabular}{cccc}
\hline Variabel & Sig & Keterangan & Hasil \\
\hline Audit Fee & 0,006 & H1 Diterima & Signifikan \\
AFM & 0,640 & H2 Ditolak & Tidak Signifikan \\
\hline
\end{tabular}

Sumber: Data Penelitian, 2021

\section{Pengaruh Audit Fee terhadap Disfungsional Auditor}

Dengan alat uji SPSS, penelitian ini menguji hipotesis menggunakan model regresi linier sederhana. Hasil uji menyatakan bahwa hipotesis pertama dinyatakan diterima. Nilai signifikansi menunjukkan hasil 0,006 maka variabel audit fee berpengaruh negatif terhadap disfungsional auditor.

Dilemma cost-quality terjadi saat adanya ketidakeseimbangan antara audit fee yang diterima dengan kualitas audit yang sesuai standar. Fee atas pekerjaan audit yang dinilai terlalu rendah menyebabkan auditor untuk menurunkan takaran time budget yang mengakibatkan tekanan bagi auditor akibat time budget yang tidak terukur secara akurat. Target penyelesaian pekerjaan yang terlalu cepat menyebabkan permasalahan serius bagi auditor. Tekanan yang dialami auditor dari manajemen tingkat atas ke bawah ini akan mendorong perilaku tereduksinya kualitas audit atau perilaku disfungsional auditor. Audit fee yang diterima dikaitkan dengan kualitas audit yang dihasilkan. Semakin berkualitas hasil audit dalam memverifikasi laporan keuangan semakin besar pula biaya yang harus dikeluarkan perusahaan. Penelitian ini konsisten dengan yang dilakukan oleh Kiryanto dan Tyas (2015). Time budget pressure memungkinkan bagi auditor untuk melakukan audit quality reduction behaviour (AQRB) yang mengarah pada perilaku disfungsional auditor.

\section{Machiavellian memoderasi pengaruh Audit Fee terhadap Disfungsional Auditor}

Hasil uji SPSS menunjukkan nilai signifikansi sebesar 0,640 yang artinya bahwa hipotesis kedua audit fee dan machiavellian sebagai pemoderasi memiliki pengaruh negatif atau tidak berpengaruh secara signifikan terhadap disfungsional auditor. Hasil penelitian ini mendukung Chasbiandani dkk (2019) yang menyatakan bahwa sifat machiavellian tidak memiliki pengaruh pada tindakan mereduksi kualitas audit yang mengarah pada disfungsional auditor. Perikatan dengan klien merupakan jalan untuk memperpanjang masa keberlanjutan KAP, sehingga auditor akan cenderung berupaya memaksimalkan keefektifan fee yang diterima tanpa berupaya melakukan tindakan disfungsional audit mengingat dampak yang ditimbulkan.

Hasil penelitian ini tidak sama dengan hasil penelitian yang dilakukan oleh Saputri dan Wirama (2015). Sifat machiavellian memiliki pengaruh positif terhadap tindakan disfungsional auditor. Seorang auditor yang mengabaikan komitmen menjunjung tinggi integritas dalam setiap penugasan audit akan cenderung mengabaikan kualitas audit. 


\section{PENUTUP}

\section{Simpulan}

Penelitian ini secara empiris membuktikan bahwa perilaku disfungsional auditor dipengaruhi oleh audit fee. Artinya bahwa seseorang dapat berperilaku mengabaikan kualitas hasil audit jika fee yang diterima dirasa tidak mampu menutupi biaya yang harus dikeluarkan selama proses pemeriksaan. Tugas audit yang berat selayaknya diimbangi dengan perolehan fee yang sesuai dengan bobot kinerja, jika tidak maka hasil audit yang akan terkena imbasnya. Namun penelitian ini juga membuktikan bahwa sifat machiavellian tidak memoderasi perilaku disfungsional auditor. Sikap mengabaikan integritas dalam menjalankan tugas tidak menguatkan auditor untuk mereduksi kualitas audit meskipun fee yang diterima rendah. Kejujuran dalam mencapai tujuan audit tetap menjadi prioritas bagi auditor meskipun fee tidak sesuai.

Penelitian ini menggunakan data primer berupa kuesioner, maka peneliti selanjutnya dapat menggunakan pendekatan lain seperti data sekunder, eksperimen atau studi kasus. Akan lebih menarik jika peneliti selanjutnya menggunakan sampel tertentu sehingga dapat memvalidasi hasil penelitian. Peneliti selanjutnya juga harus mencoba mengembangkan proxy untuk variabel lain untuk menambah dukungan praktis dan teoritis hasil penelitian.

\section{Saran}

Berikut beberapa saran dari peneliti berdasarkan hasil analisis data penelitian: a) Perlunya kesepakatan atas fee audit agar auditor dan auditee dapat menyepakati dan bekerja tanpa tekanan. Hal ini dapat dilakukan dengan cara melakukan negosiasi yang tidak memberatkan. b) Selektif terhadap auditor yang memprioritaskan integritas agar kualitas audit tidak tereduksi karena besarnya fee audit tidak mempengaruhi kinerja. c) Keterbatasan penelitian ini dalam hal jumlah sampel dan variabel yang dipilih. Saran bagi peneliti selanjutnya agar lebih memperluas jumlah sampel dan menambah variabel yang diteliti.

\section{REFERENSI}

Afsari, E. D. 2018. Pengaruh Sifat Machiavellian, Tipe Kepribadian dan Stress Kerja Terhadap Perilaku Disfungsional (Studi Empiris Pada Kantor Inspektorat di Magelang, Temanggung, dan Purworejo). Skripsi. Universitas Muhammadiyah Magelang.

Asrini, K. J., Sujana, E., dan Darmawan, N. A. S. 2014. Pengaruh Tekanan Waktu, Locus Of Control dan Tindakan Supervisi Terhadap Penghentian Prematur atas Prosedur Audit (Studi Empiris pada Kantor Akuntan Publik di Bali). Jimat Undiksha. Vol. 2, No. 1.

Avi E. D, T. O. 2018. Pengaruh Sifat Machiavellian, Pelatihan, Komitmen Profesional, ESQ, Dan Kompleksitas Tugas Terhadap Perilaku Disfungsional Auditor.Tesis. Unika Soegijapranata Semarang.

Chasbiandani, T., Satra, I., \& Rizal, N. 2019. Sifat Machiavellian dan Etika Profesi Dalam Perilaku Disfungsional Audit. Jurnal Ekonomi. Vol. 10. No. 2.

Damayanti, S., \& Sudarma, M. 2008. Faktor-faktor yang Mempengaruhi Perusahaan Berpindah Kantor Akuntan Publik. Simposium Nasional Akuntansi XI, (hal. 1- 13). Pontianak.

Dhimadhanu, Ridor. 2016. Pengaruh Asimetri Informasi, Fee Audit dan Tenure Audit Terhadap Kualitas Audit Pada Perusahaan-Perusahaan Non Keuangan Yang Terdaftar Pada LQ45. Tesis. Jurnal Fakultas Ekonomi Universitas Airlangga. Vol.5, No.1.

Griffin. R. W. 2002. Manajemen Jilid 2. Jakarta: Penerbit Erlangga. 
Kiryanto dan Tyas, A. N. 2015. Antiseden dan Konsekuensi Perilaku Disfungsional Auditor. Conference in Business, Accounting, and Management. Vol. 2, No. 1.

Martini, N. P. R. dan Pertama, I. G. A.W. 2019. Perilaku Disfungsional Auditor: Dampak Kompetensi Auditor, Sifat Machiavellian, Tekanan Waktu dan Tekanan Ketaatan (Studi Kasus Kap di Bali). Jurnal Ekonomi, Bisnis dan Akuntansi. Vol. 18, No. 1.

Muhsyi, Abdul. 2013. Pengaruh Time Budget Pressure, Resiko Kesalahan dan Kompleksitas Terhadap Kualitas Audit. Skripsi. Universitas Islam Negeri Syarif Hidayatullah.

Mukaromah, V. F. 2020. Indonesia Bersiap Alami Resesi Ekonomi, Ini Dampaknya bagi Masyarakat.

(https://www.kompas.com/tren/read/2020/09/23/070000065/indonesiabersiapalamiresesi-ekonomi-ini-dampaknya-bagi-masyarakat?page=all), diakses pada tanggal 3 Oktober 2020.

Putri, R. L. 2020. Pengaruh Sifat Machiavellian dan Locus of Control Terhadap Perilaku Disfungsional Audit Pada Kantor Akuntan Publik di Jakarta. Tesis. Universitas Atma Jaya Yogyakarta.

Riny, P. S. 2015. Pengaruh Kompleksitas Audit, Locus Of Control, Risiko Kesalahan Terhadap Penurunan Kualitas Audit Dengan Perilaku Disfungsional Auditor Sebagai Variabel Intervening (Studi Kasus Pada Kantor Akuntan Publik di Sumatera Bagian Tengah). Jom FEKON. Vol. 2, No. 2.

Santoso, Y. N. P. dan Achmad T. 2019. Pengaruh Audit Tenure, Audit Fee, Tekanan Waktu, Tekanan Klien dan Kompleksitas Tugas Terhadap Kualitas Audit Pada KAP Semarang. Diponegoro Journal of Accounting. Vol. 8, No. 4.

Saputri, I. G. A. Y., \& Wirama, D. G. 2015. Pengaruh Sifat Machiavellian dan Tipe Kepribadian pada Perilaku Disfungsional Auditor. E-Jurnal Ekonomi dan Bisnis Universitas Udayana. Vol. 4. No. 2. Pp. 70-86.

Soobaroyen, T. dan C. Chengabroyan. 2005. Auditors'Perception of TimeBudget Pressure, Premature Sign Offs and Under-reporting of Chargeable. Time: Exidence From a Developing Country[on-line] http://www.aber.ac.uk.

Sugiyono. 2011. Metode Penelitian Kuantitatif, Kualitatif, dan $R \&$ D. Bandung: Alfabeta.

Suprapto, F. M. dan Nugroho, W. C. 2020. Pengaruh Kompleksitas Tugas Terhadap Kualitas Audit Dengan Disfungsional Auditor Sebagai Variabel Moderasi. Jurnal Ilmu Akuntansi. Vol. 13, No. 2. 